\section{La Ética del Cuidado como Fundamento Bioético del Cuidado Intensivo Pediátrico Centrado en la Familia}

Alvarez-Cabrera, Cecilia Adriana

Médico pediatra Intensivista, Máster en Bioética, Instituto de Bioética, Pontificia Universidad Javeriana, Bogotá, Colombia. adrialvarez10@hotmail.com

Cuéllar-Saavedra, José Edwin

PhD en Filosofía, Especialista en Bioética, Instituto de Bioética, Pontificia Universidad Javeriana, Bogotá, Colombia

PALAVRAS-CHAVE: Ética del Cuidado; Cuidado Intensivo Centrado en la Familia

Introducción: La Unidad de Cuidado Intensivo Pediátrico (UCIP) centraliza tecnología y recursos humanos especializados, lo que la hace extraña y amenazante. Una vez el niño ingresa a la Unidad, es separado abruptamente de sus padres y familia. Su cuidado natural es suplantado por un entorno frío y distante. Allí la mortalidad es opción de desenlace. Este entorno puede generar en los niños y sus familias un desorden de estrés postraumático, con la consecuente perturbación de los procesos de adaptación y reconstrucción familiar durante y después de la estancia en la unidad, fenómeno llamado síndrome post cuidado intensivo pediátrico. El modelo de Cuidado Intensivo Pediátrico Centrado en la Familia (CIPCF) reconoce el papel esencial de la familia y sus valores emocionales, sociales y culturales como restauradores y garantes de la salud y bienestar de los niños, mitigando así el impacto del síndrome (1). Aunque es innegable el talante ético del modelo, se requiere un argumento moral que lo fundamente de forma que adquiera tal valor moral que sea inevitable promover su implementación. Nuestro objetivo es proponer la Ética del Cuidado como teoría moral que puede conseguir dicha fundamentación. Métodos: Se efectuó una investigación cualitativa documental sobre las bases teóricas de la Ética del Cuidado y del modelo Cuidado Intensivo Pediátrico Centrado en la Familia por medio de textos, revistas y publicaciones en línea y se realizó su análisis e interpretación. Resultados: Se identificaron características de la Ética del Cuidado que escudriñan la complejidad humana: relaciones y responsabilidad (2), dependencia, especificidad situacional, privilegio al conocimiento emocional, aceptación de lo indefinible y responsabilidad (3) y Cuidado como proceso (4). Se reconocieron las dimensiones del CIPCF: respeto, comunicación, valores e historia, soporte físico y emocional, y flexibilidad. Se encontró coincidencia entre ambos. Conclusiones: La ética del cuidado puede fundamentar el Cuidado Intensivo Pediátrico Centrado en la
Familia al ofrecer pilares teóricos que se entrelazan con las dimensiones del CIPCF y que pueden ser materializadas como actividad reciproca en un proceso de cuidado maduro.

AGRADECIMENTOS. Programa Maestría en Bioética, Universidad Javeriana, Bogotá, Colombia.

\section{REFERÊNCIAS}

[1] MEERT K L, CLARK J, EGGLY S. (2013). Familycentered care in the pediatric intensive care unit. Pediatr Clin North Am. (2013); 60:761-772

[2] GILligAN, C. In a Different Voice: Psychological Theory and Women's Development. $1^{\text {st }}$ ed. Cambridge: Harvard University Press; 1982.

[3] MAIO, G. Fundamentals of an Ethics of Care. En: Krause F, Boldt J, editores. Care in Health Care. Cham, Switzerland: Springer international Publishing AG; 2018. p. 51-63.

[4] TRONTO, J. Moral Boundaries, a Political Argument for an Ethic of Care. $1^{\text {st }}$ ed. New York: Routledge; 1993 